\title{
Modelling blood pressure as a continuous outcome variable in a co-twin control study
}

\author{
J T Quirk, S Berg, V M Chinchilli, B Johansson, G E McClearn, G P Vogler
}

Department of Cancer Prevention,

Epidemiology, and Biostatistics, Roswell Park Cancer Institute, A-334 Carlton House, Elm and Carlton Streets, Buffalo, NY, USA 14263 , USA J T Quirk

University College of Health Sciences, Institute of Gerontology, Jönköping, Sweden

S Berg

B Johansson

Department of Health Evaluation Sciences, College of Medicine, The Pennsylvania State University, USA V M Chinchilli

Center for

Developmental and

Health Genetics, College of Health and Human Development, The Pennsylvania State University

G E McClearn G P Vogler

Correspondence to: Dr Quirk

(jeff.quirk@roswellpark.org)

Accepted for publication 24 April 2001
The co-twin control study is a popular research design that is used in many research disciplines, including epidemiology, medicine, and the behavioural sciences. In co-twin control studies of monozygotic (MZ) exposure discordant twin pairs, the appropriate statistical tests used to analyse data from continuous outcome variables are the parametric paired sample $t$ test or the non-parametric Wilcoxon signed rank test. Results from these tests enable researchers to discover if an independent variable (the exposure) is significantly associated with the dependent variable (continuous outcome measure) while controlling for genotype, age, and sex. To date, little work has been done on modelling continuous outcome variables in co-twin control studies.

The general linear mixed model (GLMM) can be used to analyse several types of data, including repeated measurements, longitudinal, spatial, multivariate, and clustered data. As co-twin control studies yield clustered data (that is, each twin pair comprises a cluster and the members of the cluster are correlated), the GLMM provides a useful statistical approach for the regression analysis of data from co-twin control studies with continuous outcome measures. The GLMM incorporates fixed and/or random effects parameters, and assumes that a continuous outcome variable is linearly related to a set of predictor variables while allowing for possible correlation between observations (that is, lack of independent observations) and the modelling of more than one error term. ${ }^{1}$ We investigated the applicability of a linear fixed effects model in a co-twin control study of the effect of tobacco smoking on systemic arterial blood pressure in a population-based sample of Swedish twins 80 years old and older.

Table 1 Partial regression coefficients ( $\beta$ ) and standard errors (SE) for the blood pressure predictor variables in the mixed model analyses of monozygotic smoking discordant twin pairs

\begin{tabular}{|c|c|c|c|c|}
\hline & \multicolumn{2}{|l|}{ Monozygotic men } & \multicolumn{2}{|c|}{ Monozygotic women } \\
\hline & $\beta(S E)$ & $t(9), p$ value & $\beta(S E)$ & $t(9), p$ value \\
\hline \multicolumn{5}{|c|}{ Systolic blood pressure $(\mathrm{mm} \mathrm{Hg})$} \\
\hline Intercept & $164.47(12.43)$ & & $157.06(8.50)$ & \\
\hline Tobacco smoking & $22.10(13.02)$ & $1.70,0.12$ & $9.38(9.51)$ & $0.99,0.35$ \\
\hline Hypertension medication & $-11.15(18.08)$ & $-0.62,0.55$ & $3.59(11.56)$ & $0.31,0.76$ \\
\hline Age & $-5.55(5.64)$ & $-0.98,0.35$ & $1.68(3.12)$ & $0.54,0.60$ \\
\hline Body mass index & $1.29(2.30)$ & $0.56,0.59$ & $3.31(1.61)$ & $2.06,0.07$ \\
\hline Alcohol consumption & $-0.12(0.07)$ & $-1.77,0.11$ & $0.77(0.85)$ & $0.90,0.39$ \\
\hline \multicolumn{5}{|c|}{ Diastolic blood pressure $(\mathrm{mm} \mathrm{Hg})$} \\
\hline Intercept & $78.08(6.96)$ & & $84.92(4.05)$ & \\
\hline Tobacco smoking & $11.88(7.00)$ & $1.70,0.12$ & $2.60(6.12)$ & $0.42,0.68$ \\
\hline Hypertension medication & $0.28(9.98)$ & $0.03,0.98$ & $-0.20(5.93)$ & $-0.03,0.97$ \\
\hline Age & $-3.57(3.19)$ & $-1.12,0.29$ & $2.96(1.16)$ & $2.55,0.03^{\star}$ \\
\hline Body mass index & $0.69(1.27)$ & $0.54,0.60$ & $0.48(0.77)$ & $0.62,0.55$ \\
\hline Alcohol consumption & $-0.03(0.04)$ & $-0.86,0.41$ & $0.76(0.36)$ & $2.13,0.06$ \\
\hline
\end{tabular}

${ }^{\star} \mathrm{p}<0.05$ (statistically significant). The continuous regressors age (years), body mass index $\left(\mathrm{kg} / \mathrm{m}^{2}\right)$, and alcohol consumption (alcohol servings per month) were centred about their means in the mixed model analyses. The means of these regressors were 83.58 years, $24.49 \mathrm{~kg} / \mathrm{m}^{2}$, and 4.44 servings $/$ month, respectively.

\section{Methods}

This co-twin control study involved a secondary data analysis from the first measurement occasion of the OCTO-Twin Study, a five occasion, two year interval longitudinal study of Swedish octogenarian and nonagenarian twins that began in 1991. The OCTO-Twin Study has been described in detail by McClearn and colleagues. ${ }^{2}$ Smoking discordance for twin pairs was defined in a never smoked, ever smoked dichotomy (that is, one twin has never smoked, and the other is a current or former cigarette, pipe, or cigar smoker). Of the 351 twin pairs from the first measurement occasion, there were 11 male and 13 female MZ smoking discordant pairs. Systolic and diastolic blood pressure were measured by nurses using a mercury sphygmomanometer with subjects in a supine position after five minutes of rest. Paired sample $t$ tests were conducted to discover if a history of tobacco smoking was significantly associated with the blood pressure measurements in smoking discordant twin pairs.

SAS PROC MIXED was used to perform the regression analysis of the co-twin control data. $^{3}$ The overall objective of the regression analysis was to quantify the effect of tobacco smoking on a persons's systolic and diastolic blood pressure while accounting for other potential explanatory factors. These factors included age, body mass index, a dichotomous variable indicating the current use/non-use of prescription antihypertensive medication, and a monthly alcohol consumption score. For the two zygosity by sex groups, separate variancecovariance matrices were modelled for the blood pressure variables. As it was not necessary to model fixed and random effects simultaneously in our data analyses, random 
effects were not specified. All data analyses were performed using SAS version 6.12 running on a UNIX workstation. An $\alpha$ level of 0.05 was used for all statistical tests.

\section{Results}

The results from the paired sample $t$ tests showed that the $M Z$ male smokers had higher mean (SD) systolic (181.0 (36.9) $\mathrm{mm} \mathrm{Hg} t(9)$ $=1.83, p=0.10)$ and diastolic (93.5 (18.9) $\mathrm{mm} \mathrm{Hg} ; t(9)=2.49, p=0.03$ ) blood pressures than the MZ male non-smokers (161.5 (15.8) and 80.5 (10.9) $\mathrm{mm} \mathrm{Hg}$, respectively). $\mathrm{MZ}$ female smokers also had higher mean systolic $(165.0$ (28.0) $\mathrm{mm} \mathrm{Hg} ; t(10)=1.20, p=0.26)$ and diastolic $(85.9$ (14.3) $\mathrm{mm} \mathrm{Hg} ; t(10)=$ $0.65, p=0.53$ ) blood pressures than the $\mathrm{MZ}$ female nonsmokers (152.7 (21.6) and 81.8 (15.2) $\mathrm{mm} \mathrm{Hg}$, respectively), although these differences were not statistically significant.

The results from the regression analyses of the co-twin control data are presented in table 1. For systolic blood pressure, the $t$ tests of the regression parameter estimates were not statistically significant for any of the predictor variables in either zygosity by sex group. For diastolic blood pressure, the $t$ tests of the regression parameter estimates were found to be statistically significant for age in $\mathrm{MZ}$ women.

\section{Discussion}

The results of this investigation demonstrate that a linear fixed effects model provides a more useful and comprehensive analysis of the co-twin control data compared with the paired sample $t$ test. The linear model analyses extended the traditional co-twin control study of smoking discordant twin pairs by accounting for some of the factors that the current literature suggests might influence blood pressure measurements in a sample of elderly persons. ${ }^{45}$ After statistically controlling for the effects of age, body mass index, alcohol consumption, and antihypertensive medication use, it was concluded that a history of tobacco smoking was not significantly associated with either systolic or diastolic blood pressure in MZ smoking discordant twin pairs. This absence of significance might be attributable to the small sample of discordant twins available for analysis (that is, low statistical power), or possibly as a result of a non-linear relation between the blood pressure outcome variables and a history of tobacco smoking. Nevertheless, the GLMM provides a very powerful statistical approach for data analysis of co-twin control studies. For example, although our presentation here does not pursue it, the GLMM can accomodate repeated measurements on each twin pair over time. In such a scenario, fixed and random effects parameters could be modelled simultaneously. Future research should continue to explore and expand the use of the GLMM in many types of twin research designs, including longitudinal, repeated measurements, and co-twin control studies.

This research was completed when Jeffrey Quirk was at the Center for Developmental and Health Genetics at the Pennsylvania State University.

Funding: this work was supported by the National Institute on Aging (grant AG08861) of the National Institutes of Health.

Conflicts of interest: none.

1 Cnaan A, Laird NM, Slasor P. Using the general linear mixed model to analyse unbalanced repeated measures and longitudinal data. Stat Med 1997;16:2349-80.

2 McClearn GE, Johansson B, Berg S, et al. Substantial genetic influence on cognitive abilities in twins 80 or more genetic influence on cognitive abilities
years old. Science 1997;276:1560-3.

3 Littell RC, Milliken GA, Stroup Ww, et al. SAS system for Littell RC, Milliken GA, Stroup WW, et al. SAS
mixed models. Cary, NC: SAS Institute Inc, 1996.

mixed models. Cary, NC: SAS Institute Inc, 1996.
4 World Health Organization. Epidemiology and prevention of cardiovascular diseases in elderly people: Report of a WHO study group. World Health Organ Tech Rep Ser 1995; 853.

5 World Health Organization. Hypertension control: Report of a WHO expert committee. World Health Organ Tech Rep Ser $1996 ; 862$. 